\title{
RADIOCARBON DATING WITH THE UTRECHT TANDEM ACCELERATOR
}

K VAN DER BORG, JA HOOGENBOOM, RA JELMERSMA, ABRAHAM VERMEER

Fysisch Laboratorium Rijksuniversiteit Utrecht PO Box 80.000, 3508 TA Utrecht, The Netherlands

and

\section{GERT HUT}

Laboratorium voor Isotopen Fysica, Rijksuniversiteit, Groningen, The Netherlands

\section{INTRODUCTION}

In 1979 when accelerator mass spectrometry was started in the Netherlands, Gove (1978) and Litherland (1980) demonstrated that a tandem accelerator is eminently suited for this work. Isotope ratios below $10^{-15}$ could be determined and applications were stimulated on numerous fields of research. ${ }^{14} \mathrm{C}$ dating in particular would become an important application because smaller samples could be employed and more complex dating problems could be attacked. However, the 5\% accuracy reached at that time had to be improved towards the $0.5 \%$ obtained with the conventional method of counting decays. Purser and Hanley (1978) pointed out that this high accuracy could be reached in facilities especially dedicated to dating. Rapid switching between measurements on different isotopes turned out to be crucial (Suter et al, 1981). We decided to proceed in two phases. In the first phase, the existing EN-tandem facility would be used as before and modified for the detection of $14 \mathrm{C}$ ions. From measurements with ${ }^{14} \mathrm{C}$ ions from different samples, information would be obtained about the limitations of the existing facility. In the second phase, this information would be used to develop a facility in which accurate measurements of isotope ratios can be performed for elements throughout the periodic system. Conventional ${ }^{14} \mathrm{C}$ dating will be extended in collaboration with the Isotope Physics Laboratory in Groningen. Also, applications with other elements will be studied. The improved facility is scheduled for operation in the spring of 1983.

\section{EXPERIMENTAL ARRANGEMENT AND METHOD}

In analogy with laboratories where accelerator mass spectrometry was born, accelerator technology for stable heavy-ion beams of high intensity and heavy-ion detection techniques had to be developed. A sputter ion source of the Aarhus type - (Tykeson et al, 1975) was constructed because the existing duoplasmatron showed a serious memory effect. Carbon samples with known ${ }^{14} \mathrm{C} /{ }^{12} \mathrm{C}$ ratios were prepared for this source from either charcoal of $\mathrm{CO}_{2}$. Charcoal conventionally dated in 
Groningen with an accuracy of $0.5 \%$ was used in the form of manganese carbide. Stable ${ }^{12} \mathrm{C}^{-}$currents between 2 and $4 \mu \mathrm{A}$ were obtained with these samples for periods of several hours. In a new set-up, similar to that of Beukens and Lee (1981), carbon samples were obtained by rf-cracking of acetylene, prepared from $\mathrm{CO}_{2}$. Carbon samples with different ${ }^{14} \mathrm{C} /{ }^{12} \mathrm{C}$ ratios were obtained with $1 \%$ accuracy by using, ac€tylene obtained by mixing amounts of this gas with known ${ }^{14} \mathrm{C} /{ }^{12} \mathrm{C}$ ratios. During a period of an hour ${ }^{12} \mathrm{C}^{-}$currents up to $7 \mu \mathrm{A}$ were obtained from these samples. A gas-filled heavy-ion detector of the Rochester design (Gove, 1978) was constructed. It combines a resistive wire counter for position read-out and an ionization chamber for measurement of energy loss and total energy of the ions. A $13^{\circ}$ electrostatic analyser with $\mathrm{E} / \Delta \mathrm{E}=200$ was constructed to reduce the background of ions in the detector. Spirally-inclined field acceleration tubes were installed in the high-energy part of the tandem in order to reduce the heavy load of the terminal and, hence, to obtain a more stable beam transmission. A generating voltmeter stabilization circuit was developed to stabilize the terminal voltage within $0.1 \%$ during acceleration of ${ }^{14} \mathrm{C}$ ions when the slit stabilization system cannot be used.

The measurements were made with the EN-tanden: facility (fig 1). Negative ions with an energy of $25 \mathrm{keV}$ emerging from the sputter source were mass-analyzed with the $20^{\circ}$ inflection magnet with $\mathrm{m} / \Delta \mathrm{m} \simeq 20$ and were focused with Einzel lenses in

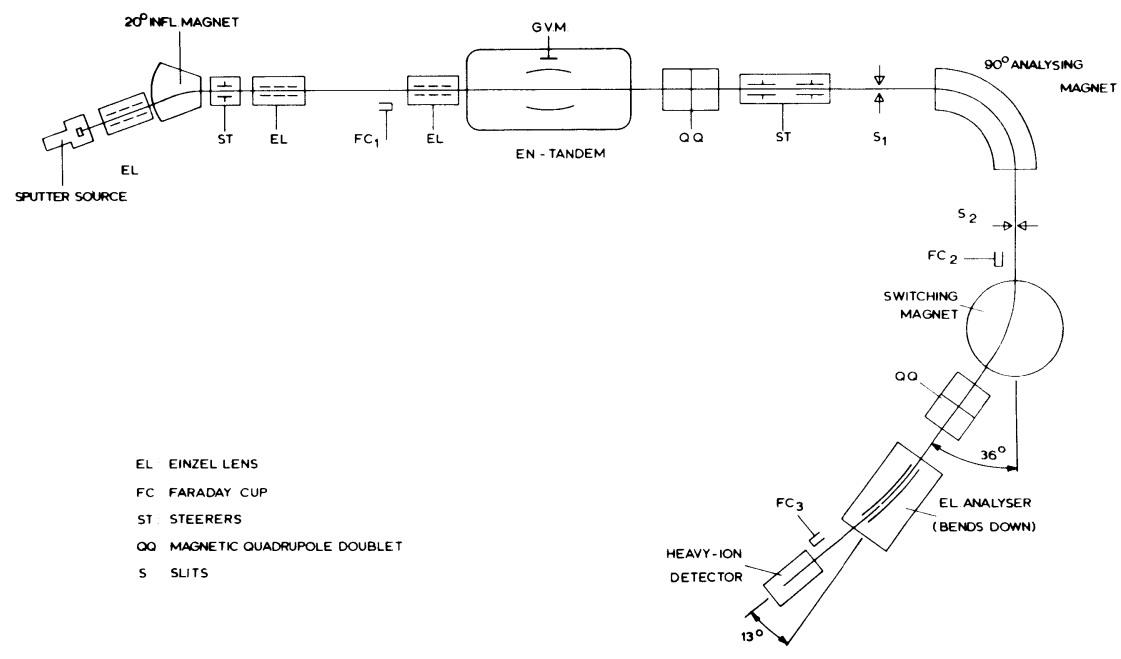

Fig 1. Schematic experimental arrangement of the present Utrecht EN-tandem facility 
the stripper of the tandem accelerator. The terminal voltage was set at 4.35 MV to obtain optimal stripping efficiency for 4+ ions. The icns emerging from the accelerator were focused with a magnetic quadrupole doublet in the object slits of the $90^{\circ}$ analysing magnet with exit slits set at $\mathrm{p} / \Delta \mathrm{p} \simeq 500$. The switching magnet bent the beam over $36^{\circ}$ into the beam line used, where another magnetic quadrupole doublet focused the beam through the electrostatic analyser. ${ }^{14} \mathrm{C}$ ions were detected in the heavy-ion detector and ${ }^{12} \mathrm{C}$ and ${ }^{13} \mathrm{C}$ currents measured in a Faraday cup which can be placed pneumatically just in front of the detector. Signals of the detector with information on position, energy loss, and total energy of the detected ions were digitized by 11-bit ADC's, connected with a CAMAC interface to a PDP $11 / 34$ computer for on-line data handling. Figure 2 shows the two-dimensional display of the data on a graphics terminal, used for event selection.

In order to determine ${ }^{14} \mathrm{C} /{ }^{12} \mathrm{C}$ ratios, the accelerator and beam transport elements were tuned for optimal transmission of a ${ }^{12} \mathrm{C}$ beam. Then tuning was done for a ${ }^{13} \mathrm{C}$ beam. The best transmission was $50 \%$, taking stripping efficiency into account. Settings for the ${ }^{14} \mathrm{C}$ beam were obtained by scaling the magnetic elements. Further optimization of all these magnetic elements was extremely important. Hence, reproducible settings are required for the periodic measurement of ${ }^{14} \mathrm{C}$ ions alternated with ${ }^{12} \mathrm{C}$ and ${ }^{13} \mathrm{C}$ currents. However, the reproducibility proved insufficient. In particular, accelerator tuning for the intense ${ }^{12} \mathrm{C}$ beam differed from that for the weak ${ }^{13} \mathrm{C}$ and ${ }^{14} \mathrm{C}$ beams. Moreover, the interchange from slit stabilization to generating

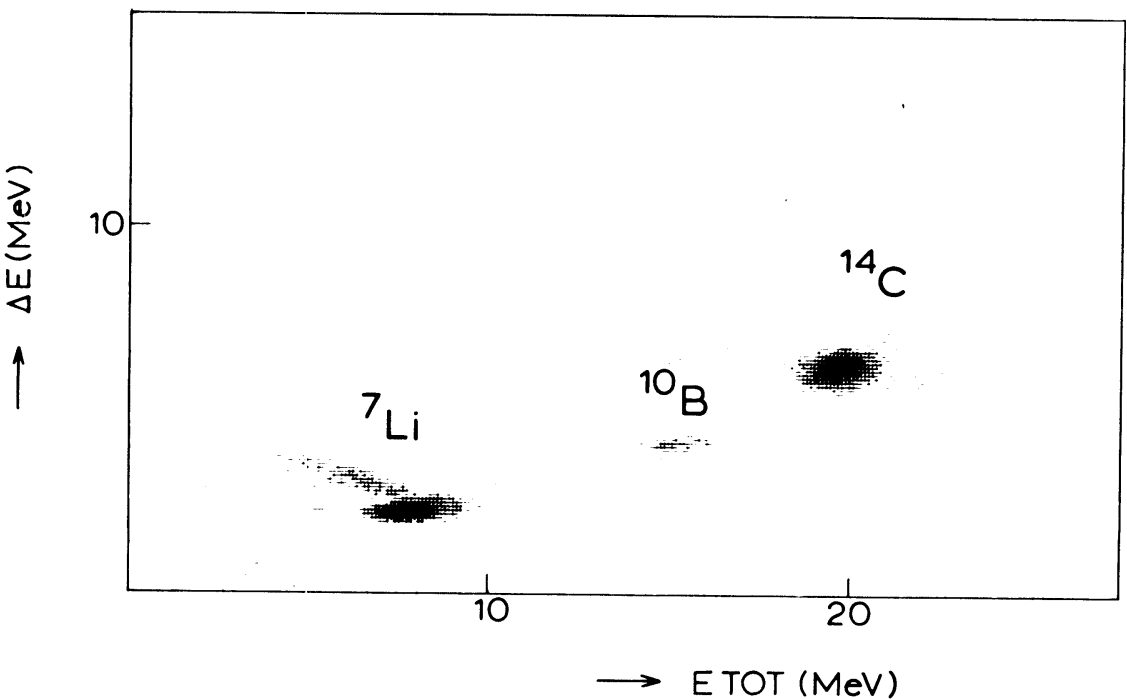

Fig 2. Two dimensional display of energy loss $\Delta \mathrm{E}$ vs total energy $E_{\text {tot }}$ 
voltmeter (GVM) stabilization also caused a drop in transmission. Since it was impractical to measure sequentially ${ }^{14} \mathrm{C}$ ions and both the ${ }^{12} \mathrm{C}$ and ${ }^{13} \mathrm{C}$ currents, we only alternated with the ${ }^{13} \mathrm{C}$ current, which did not reproduce wel1 within $10 \%$. This could be due either to changes in the performance of the sputter source or to instabilities in the beam transmission. Thus, measurement of ${ }^{14} \mathrm{C}$ ions was made in short periods of 5 to 10 minutes, when ca $1000{ }^{14} \mathrm{C}$ ions were counted. Measuring 1 sample consisted of ca 5 short measurements. Samples were changed by inserting a new sample in the sputter source. Taking into account the lower stripping efficiency of ca $3 \%$ for the ${ }^{14} \mathrm{C}$ ions with respect to the ${ }^{13} \mathrm{C}$ ions at the terminal voltage used, the ${ }^{14} \mathrm{C} /{ }^{13} \mathrm{C}$ ratios obtained for the different samples were converted into percentages of modern carbon (pmC). The statistical errors of ca $3 \%$ for the short measurements were small with respect to the large systematic errors.

\section{RESULTS}

Table 1 shows the results for a series of short measurements obtained with a carbon sample prepared with the rfcracking method with a ${ }^{14} \mathrm{C} /{ }^{12} \mathrm{C}$ ratio of $154.4 \mathrm{pmC}$. The values show large systematic errors and the average value of $67 \pm 10$ $\mathrm{pmC}$ is considerably lower than the expected value. Similar results were obtained for measurements made under the same experimental conditions with rf-cracked samples of different ${ }^{14} \mathrm{C} /{ }^{12} \mathrm{C}$ ratios. Figure 3 shows the results of these accelerator measurements compared to values obtained with $1 \%$ accuracy in the conventional decay-counting method. The same observation was made as in table 1: large systematic errors occur and average values obtained with the accelerator method are too small by about a factor of two. Similar results were obtained in other experimental runs with different samples. Mostly, the ${ }^{14} \mathrm{C}$ yield was too small, but the difference with expected values was not constant. Nevertheless, the data show a linear dependence on the ${ }^{14} \mathrm{C} /{ }^{12} \mathrm{C}$ ratio present in the sample, indicating that relative dating can be done with present accuracy as low as $20 \%$.

TABLE 1. Results obtained for a ${ }^{1 / 4} \mathrm{C}$ measurement with a carbon sample containing $154.4 \mathrm{pmC}$

\begin{tabular}{cccc}
$\begin{array}{c}\text { Running time } \\
(\mathrm{sec})\end{array}$ & ${ }^{1{ }^{4} \mathrm{C} \text { counts }}$ & $\begin{array}{c}{ }^{3} \mathrm{C} \text { current } \\
(\mathrm{nA})\end{array}$ & $\begin{array}{c}{ }^{14} \mathrm{C} /{ }^{12} \mathrm{C}^{* *} \\
(\mathrm{pmC})\end{array}$ \\
\hline 146 & 501 & 27 & 79 \\
595 & 3155 & 45 & 73 \\
297 & 1794 & 53 & 65 \\
296 & 1654 & 60 & 58 \\
297 & 1733 & 65 & 57 \\
\hline
\end{tabular}

* pmC means percentage of modern carbon; 100 pmC corresponds to ${ }^{1{ }^{4}} \mathrm{C} /{ }^{12} \mathrm{C}=1.18 \times 10^{-12}$

** Corrected for $3 \%$ lower stripping efficiency of ${ }^{14} \mathrm{C}$ ions with respect to ${ }^{13} \mathrm{C}$ ions 


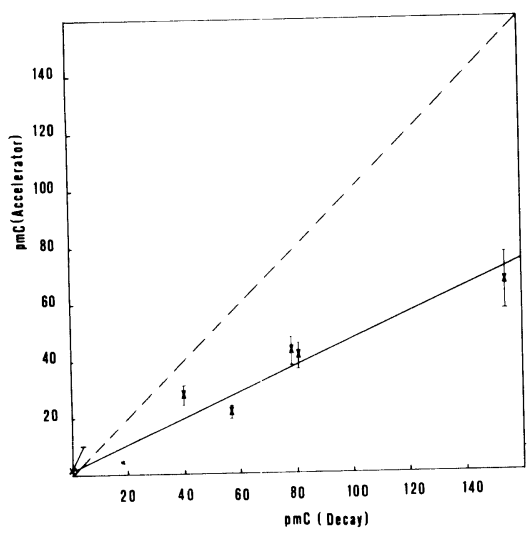

CONCLUSION
Fig 3. Comparison of results from the accelerator method and the conventional method of counting decays. The slope of the full line drawn through the data is too small with respect to the dashed line representing the expected values.

Our results show that the combination of electrostatic analyser and heavy-ion detector provides good identification of ${ }^{14} \mathrm{C}$ ions. Sample preparation is satisfactory, especially the new facility for the rf-cracking method which can create carbon samples from very little material. ${ }^{14} \mathrm{C} /{ }^{12} \mathrm{C}$ ratios determined for different samples show a linear dependence on the ratios determined in Groningen, indicating that relative dating measurements are possible with low accuracy. Absolute values of the obtained ratios are too small and show large systematic errors. These shortcomings can be ascribed to the poor beam transmission through the accelerator. The best transmission of $50 \%$ indicates that a considerable fraction of the beam is lost. Since the loss occurs in an undefined way, small changes in the performance of the accelerator or in the settings of the beam transport elements cause larger changes in beam transmission. Hence, it is difficult to obtain reproducible settings for optimal beam transmission of the different isotopes. Also, it is a drawback that the present ion source is not provided with a sample wheel. Interchange of samples involves the shutdown of the ion source, introducing a change in performance for different samples.

We have decided to improve the beam transmission in order to realize the future determination of isotope ratios within $1 \%$ accuracy. Beam transport calculations with the computer code OPTRYK (Greenway, 1978 pers commun) were made to develop a new injection system with optimal beam transmission. This injection system involves: 1) a $90^{\circ}$ magnet with $\mathrm{m} / \Delta \mathrm{m} \simeq 300$, 2) preacceleration to $120 \mathrm{keV}, 3)$ an electrostatic quadrupole triplet lens, 4) spirally-inclined field tubes in the low-energy part of the tandem. A gridded lens in the entrance of the first tube facilitates optimal focusing in the stripper.

Rapid switching between measurements on different isotopes 
will achieve reproducible and accurate measurement of the different isotopes. Rapid switching will be obtained by electrostatically biasing the vacuum chamber of the injection magnet, so that at a fixed magnetic field, ions of different mass can be injected in short periods by adjusting the energy of the ions. The stable isotopes will be injected in short periods of ca $100 \mathrm{\mu s}$ to prevent instabilities in accelerator performance due to the intense ${ }^{12} \mathrm{C}$ beam. The experimental arrangement with pulsed beams will become similar to the EN-tandem facility in Zürich (Suter et al, 1981). Different isotopes with the same energy emerging from the accelerator pass through the electrostatic analyser and are separated with a $90^{\circ}$ analyzing magnet. With computer control, the ${ }^{14} \mathrm{C}$ ions are counted in the heavy-ion detector and ${ }^{12} \mathrm{C}$ and $13_{\mathrm{C}}$ currents are measured in separate Faraday cups located in the focal plane of the magnet. Another improvement is expected from a new sputter ion source similar to the Argonne design (Yntema and Billquist, 1982). Early tests showed that ${ }^{12} \mathrm{C}^{-}$currents up to $80 \mu \mathrm{A}$ could be obtained from a spot of $1 \mathrm{~mm}$ diameter on a graphite sample. At the moment, the sample wheel can contain eight samples.

\section{REFEREINCES}

Beukens, RP, Lee, HW, The production of small carbon samples by re-dissociation of acetylene, Symp on accelerator mass spectrometry, Proc: I1linois, Argonne Nat1 Lab, p 416-425.

Gove, HE, ed, 1978, Conf on radiocarbon dating with accelerators, 1st, Proc: New York, Univ Rochester.

Litherland, AE, 1980, Ultrasensitive mass spectrometry with accelerators: Ann Rev Nuclear Particle Sci, v 30, p 437-473.

Purser, KH, Hanley, PR, A carbon-14 dating system, Conf on radiocarbon dating with accelerators, 1st, Proc: lNew York, Univ Rochester, p 165-186.

Suter, M, Balzer, R, Bonani, G, Stoller, CH, Wölfli, W, Beer, J, Oeschger, H, Stauffer, B, 1981, Improvements in the application of a tandem Van de Graaff accelerator for ultrasensitive mass spectrometry, in symp on accelerator mass spectrometry, Proc: Illinois, Argonne Nat1 Lab, p 87-99

Tykeson, P, Anderson, HH, Heinemeier, J, 1975, Further investigations of ANIS: IEEE Trans Nuc1 Sci 1, v NS23, p 1104-1108

Yntema, JL and Billquist, PJ, 1982, High intensity inverted sputter source; Nuclear Instruments Methods, v 199, p $637-638$. 